\title{
Cytological response of palatal epithelium to TiN-coated CoCr alloy denture
}

\author{
Monika Łukomska-Szymańska ${ }^{1}$, Piotr M. Brzeziński ${ }^{2}$, Andrzej Zieliński ${ }^{2}$, \\ Jerzy Sokołowski ${ }^{1}$
}

\author{
${ }^{1}$ Department of General Dentistry, Medical University of Lodz, Poland \\ ${ }^{2}$ Department of Cytophysiology, Histology and Embryology, Medical University of Lodz, Poland
}

\begin{abstract}
The aim of this study was to assess the impact of titanium nitride coatings on $\mathrm{CoCr}$ alloy metal parts in framework dentures on human palatal epithelium cytology compared to framework dentures made with the same alloy but without titanium nitride coating, and to acrylic dentures. Every prosthetic restoration introduced into the oral cavity and remaining in direct contact with the palate exhibits a varied and harmful effect on the state of the palatal epithelium by disturbing its keratinization. $\mathrm{CoCr}$ alloy dentures produce a significantly greater perturbation of keratinization compared to acrylic dentures. There is no evidence showing that a titanium nitride coating of the $\mathrm{CoCr}$ alloy plays a protective role in the environment of the oral cavity. (Folia Histochemica et Cytobiologica 2012, Vol. 50, No. 1, 104-110)
\end{abstract}

Key words: TiN coating, CoCr alloy, palatal epithelium, cytological changes

\section{Introduction}

Noble and non-noble metal alloys are routinely used in prosthodontics. Noble metal (such as gold) alloys are often substituted with cheaper cobalt-chrome $(\mathrm{CoCr})$ or nickel-chrome $(\mathrm{NiCr})$ alloys for financial reasons. One of the required properties of prosthodontic biomaterials is biocompatibility. This is defined as the ability of a material to elicit an appropriate biological response in a given application. However, compared to noble metals alloys, $\mathrm{CoCr}$ and $\mathrm{NiCr}$ alloys evoke significantly higher deleterious local and systemic effects in the body [1].

The side effects of prosthetic restorations usually result from toxicity, but can also stem from the allergenic propensity of the materials from which the restorations are made [2]. In particular, ingredients of $\mathrm{NiCr}$ and $\mathrm{CoCr}$ alloys such as nickel, cobalt, chromium, and molybdenum, exhibit strong effects on the

Correspondence address: M. Łukomska-Szymańska,

Department of General Dentistry,

Medical University of Lodz,

Pomorska Str. 251, 92-213 Lodz, Poland;

e-mail: monika.lukomska-szymanska@umed.lodz.pl body cells and tissues and elicit toxic and morphological effects as well as cellular metabolic disorders [2-8]. On the other hand, allergic reactions to metals such as $\mathrm{Ni}, \mathrm{Cr}, \mathrm{Co}, \mathrm{Pd}, \mathrm{Au}, \mathrm{Cu}$ and $\mathrm{Ag}$ found in restorative materials vary depending on gender [3] and profession [4]. It is estimated that around $10 \%$ of women and about $1 \%$ of men are allergic to nickel. Allergies to chromium salts are found in less than $1 \%$ of both genders. Allergies to palladium $[8,9]$ and to gold, cobalt and copper [9] usually accompany nickel salt allergies. Previously, allergic reactions in the oral cavity to chromium alloys or in patients with metal restorations were thought to be exceptionally rare [10], but in recent years the number of patients with diagnosed dermal allergies to the most commonly used metal alloy components has grown rapidly [3, 4, 11-14].

Efforts have been made to find various methods of nobelizing the metal surfaces of restorations made of $\mathrm{CoCr}$ and $\mathrm{NiCr}$ alloys in order to prevent or limit the deleterious (toxic/allergenic) effects of metal containing restorations on the tissues of the oral cavity, especially those in direct contact with the metals. One of these methods involves covering the surface with protective layers of titanium nitride [15] designed to prevent metal corrosion and the consequent release 
of corrosion products and metal ions which are harmful to the surrounding tissue. Evaluating the properties of metallic materials and nobelizing methods, and the rejection of certain alloys due to their undesirable effect on the human body, can only be achieved through in vivo and in vitro studies [16, 17].

Acrylic dentures are often irreplaceable in some clinical conditions; therefore they were included into the study. Acryl can be considered as an alternative material to metal alloys in Kennedy Class 1 or 2 cases. Inclusion of this study group gives the opportunity to show only acrylic resin effect on the human palatal epithelium.

The aim of this study was to assess the impact of titanium nitride coatings on $\mathrm{CoCr}$ alloy metal parts in framework dentures on human palatal epithelium cytology compared to framework dentures made with the same alloy but without titanium nitride coating, and to acrylic dentures.

\section{Material and methods}

The study was carried out on 120 patients divided into four groups: one control group and three experimental groups. The control group consisted of 27 subjects of both genders (aged $47.0 \pm 12.4$ years) not using framework dentures. The remaining 93 patients who randomly reported for a prosthodontic follow-up visit were divided into three groups according to the type of material used in their dentures. Group I (ACRYL) consisted of 30 patients of both genders (aged $59.1 \pm 10.9$ years) who had been using acrylic dentures for $5.5 \pm 2.8$ years. Group II $(\mathrm{CoCr})$ consisted of 39 patients of both genders (aged $55.6 \pm 10.7$ ) years who had been using CoCr alloy framework dentures for $5.74 \pm 2.73$ years. Group III (CoCrTN) consisted of 24 patients of both genders (aged $56.7 \pm 1.3$ years) who had been using titanium nitride-coated $\mathrm{CoCr}$ alloy framework dentures for $1.85 \pm 0.7$ years. All patients were classified as ASA PS 1 (normal healthy patient - no organic, physiologic, or psychiatric disturbance; excludes the very young and very old; healthy with good exercise tolerance), non-smoking and with good oral hygiene. Dentures were tooth-tissue borne, while the opposing teeth were either natural dentition or fixed dental prostheses. The metal framework of the dentures was polished and the acrylic dentures were matt finished. The acrylic dentures were heat-cured and they were not relined during the study observation period.

Smear tests. Palatal epithelium smear tests were carried out using the Silverman method [8]. Epithelial cells from a previously dried gingival fragment were harvested by the steady movement of a sodium chloride-moistened cotton swab. The smear test was performed on a microscope slide and fixed immediately afterwards with a spray solution of isopropyl alcohol with methanol. Following desiccation and rehydration, the sample was stained via standard procedure with Shorr (Merck) staining solution, and the cell nuclei were stained with Harris hematoxylin; after dehydration and passing through xylene, the sample was closed in Canada balsam with a cover slip. The samples were studied with a biological light microscope at $400 \times$ magnification. At least 200 successive epithelial cells were examined in each sample. The frequency of the following types of cells in the epithelium was counted:

- acidophilic cells - corresponding to superficial keratinized cells (mature) of the stratified squamous epithelium, with or without nuclei (including pyknotic nuclei), with acidophilic staining of the cytoplasm (from amaranth through dark orange to bright yellow color);

- multi-staining cells - corresponding to non-keratinized superficial cells of the stratified squamous epithelium, with irregular contours, basophilic cytoplasm (green-blue hue) containing acidophilic-staining (red to amaranth hues) granules or surfaces (resembling map drawing), sometimes containing a shrunken nucleus. Nucleus-free cells with the cytoplasm stained greenyellow or orange were also included in this group;

- basophilic cells - corresponding to immature cells of the spinous or parabasal layers of the stratified oral epithelium, usually exhibiting a polygonal shape or less commonly an oval shape, with cytoplasm staining green or blue-green), with a centrally located nucleus containing chromatin granules.

Following these characteristics, cells were grouped as: acidophilic including nuclei-containing acidophilic cells; multi-staining including nuclei-containing multi-staining cells; or basophilic nuclei-containing cells.

The frequency of cell foci, neutrophils, erythrocytes and bacteria was measured. The amount of epithelial cell foci, granulocytes, erythrocytes and bacterial cells was assessed using the following criteria: 1) none - absence of the given element in the sample; 2) rare - small amount of the given element (up to ten per field of view and not in each field of view); 3) several — the same amount as in 'rare' but in every field of view; 4) numerous - up to 50 per field of view; 5 ) very numerous - more than half of each field of view covered with the given cell type; 6) massive - entire field of view except keratinocytes filled with the element. In category 6, cellular foci were termed 'patches' corresponding to the foci presence of many adjoining cells (usually) from neighboring epithelium layers.

Statistical analysis. All collected data on the frequency of the various cell categories was analyzed statistically using the following tests: descriptive statistics (mean value, standard deviation), analysis of the distribution of the obtained results (Chi-square, Kolmogorov-Smirnov, skewness and kurtosis tests), variance analysis (test F), assessment of dif- 
ferences between normal distribution means (parametric ANOVA with Newman-Keuls post-test), assessment of differences between non-normally distributed means (median test - Mann-Whitney U test and the Chi-square test for independence).

\section{Results}

The patients' ages and period of wearing dentures followed a normal distribution. A comparison of the differences between means (parametric ANOVA with Newman-Keuls post-test) showed that no significant differences existed between the control group and all the other study groups (ACRYL p > 0.05; CoCr $p>0.05$; CoCrTN $p>0.05)$. In terms of age differences and time using dentures, no statistically significant differences were noted. The frequencies of epithelial cellular foci, erythrocytes, neutrophils and bacteria in the tested palatal epithelium smears are shown in Table 1.

The presence of keratinocyte foci was not observed in $81 \%$ of the patients from the control group. Granulocytes were not present, rarely present or only several were present in smears from $88 \%$ of the subjects. Erythrocytes in these subjects occurred with a similar frequency (lack of them in $88 \%$ of cases). The presence of bacterial cells was not noted in $51 \%$ of palatal epithelium smears, and were only rare or several in another $35 \%$ of patients.
The obtained palatal epithelium cytology results were compared as follows: 1) control - compared with each of the three prosthetic groups: $\mathrm{CoCr}-$ CoCr alloy dentures, CoCrTN - CoCr alloy with titan nitride coating dentures, and ACRYL - acrylic dentures; and 2) between the groups of patients with different types of denture.

The following statistically significant differences were noted between the control group and the $\mathrm{CoCr}$ alloy group. In the category of all acidophilic cells, in the $55-70 \%$ range $\left(\mathrm{chi}_{\alpha}^{2}=7.50802\right)$, significant differences occurred in approx. $30 \%$ of the patients, while not being found at all in the control group. No differences were noted in the category of multi-staining cells. Statistical differences were found in three ranges of the cells with nuclei: $0-20 \%\left(\mathrm{chi}_{\alpha}{ }_{\alpha}=\right.$ $=7.99976), 40-70 \%\left(\mathrm{chi}_{\alpha}{ }_{\alpha}=5.05114\right)$ and $70-100 \%$ $\left(\mathrm{chi}^{2}{ }_{\alpha}=6.93\right)$. In the first of these ranges, the patients wearing $\mathrm{CoCr}$ alloy dentures were a minority (only $20.5 \%$ of the subjects) compared to the control group (77.7\% of the patients). Patients with CoCr alloy dentures dominated in the other two mentioned ranges: they made up $38 \%$ (compared to $7.7 \%$ of the control group) of the $40-70 \%$ range and $28.2 \%$ of the $70-$ $-100 \%$ range in which there were no patients from the control group.

In all, at least $65 \%$ of the patients with CoCr alloy dentures exhibited large percentages of nuclei-containing cells in the epithelial palate smear (Figure 1C).

Table 1. Analysis results of the epithelial foci frequency, erythrocytes, neutrophils and bacterial cells in the tested palatal epithelium smears

\begin{tabular}{|l|c|c|c|c|c|c|c|c|c|}
\hline \multicolumn{9}{|c|}{ Epithelial cell foci } & \multicolumn{5}{c|}{ Neutrophils } \\
\hline & Control & ACRYL & CoCr alloy & $\begin{array}{c}\text { CoCr } \\
\text { alloy/TiN }\end{array}$ & Control & ACRYL & CoCr alloy & $\begin{array}{c}\text { CoCr } \\
\text { alloy/TiN }\end{array}$ \\
\hline None & 0.810 & 0.700 & 0.652 & 0.500 & 0.630 & 0.600 & 0.326 & 0.417 \\
\hline Rare & 0.074 & 0.000 & 0.130 & 0.125 & 0.111 & 0.100 & 0.130 & 0.292 \\
\hline Several & 0.037 & 0.033 & 0.043 & 0.000 & 0.148 & 0.261 & 0.435 & 0.083 \\
\hline Numerous & 0.000 & 0.000 & 0.065 & 0.083 & 0.037 & 0.033 & 0.065 & 0.083 \\
\hline Very numerous & 0.000 & 0.000 & 0.022 & 0.083 & 0.037 & 0.000 & 0.022 & 0.083 \\
\hline Patches & 0.074 & 0.267 & 0.087 & 0.208 & 0.037 & 0.000 & 0.000 & 0.042 \\
\hline & & Erythrocytes & & & & Bacteria \\
\hline & Control & ACRYL & CoCr alloy & $\begin{array}{c}\text { CoCr } \\
\text { alloy/TiN }\end{array}$ & Control & ACRYL & CoCr alloy & CoCr \\
\hline None & 0.889 & 0.933 & 0.848 & 1.000 & 0.519 & 0.533 & 0.348 & 0.333 \\
\hline Rare & 0.037 & 0.000 & 0.000 & 0.000 & 0.148 & 0.100 & 0.261 & 0.167 \\
\hline Several & 0.000 & 0.033 & 0.065 & 0.000 & 0.296 & 0.333 & 0.326 & 0.417 \\
\hline Numerous & 0.074 & 0.033 & 0.065 & 0.000 & 0.037 & 0.000 & 0.065 & 0.083 \\
\hline Very numerous & 0.000 & 0.000 & 0.022 & 0.000 & 0.000 & 0.033 & 0.000 & 0.000 \\
\hline Massive & 0.000 & 0.000 & 0.000 & 0.000 & 0.000 & 0.000 & 0.000 & 0.000 \\
\hline
\end{tabular}



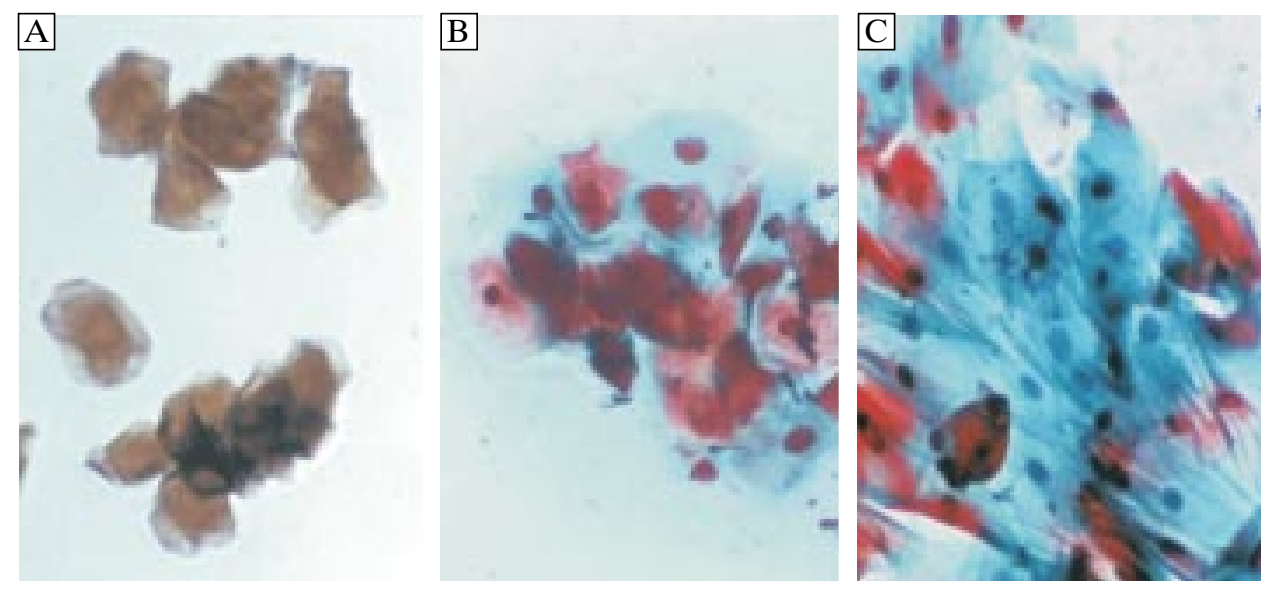

Figure 1. A. Acidophilic cells without nuclei from the superficial layer of stratified squamous epithelium in patient from control group; B. Acidophilic, multi-staining and basophilic cells with nuclei from the superficial and spinous layer of the stratified oral epithelium in patient from ACRYL group; C. Basophilic and multi-staining cells with nuclei from the superficial and spinous layer of the stratified oral epithelium in patient from CoCr group. Shorr method.

Magnification $\times 400$

Patients from the CoCr group appeared significantly less frequently $(33.3 \%$ compared to $81.4 \%$ for the control group) in the acidophilic cells with nuclei category and with a relatively low percentage (0-20\%) of this cell type $\left(\mathrm{chi}_{\alpha}^{2}=4.41089\right)$. Significant differences were noted between the control group and the CoCr group in three successive ranges: $0-12 \%, 12-$ $-24 \%$ and $24-36 \%$ - of the multi-staining cell category with $\mathrm{chi}^{2}{ }_{\alpha}=5.12414, \mathrm{chi}^{2}=8.07955, \mathrm{chi}^{2}{ }_{\alpha}=$ $=4.54447$, respectively. In the $0-12 \%$ range were found $96 \%$ of control group patients and only $38 \%$ of the CoCr group patients, whereas only patients with $\mathrm{CoCr}$ alloy dentures were found in the $12-24 \%$ and $24-36 \%$ range, with no patients from the control group.

In all, more than $60 \%$ of the $\mathrm{CoCr}$ group patients belonged to the ranges with more than $12 \%$ of multistaining cells with nuclei. No differences were found in the category of basophilic cells with nuclei between the control group and the CoCr group. A comparative analysis of the control group with the CoCrTN group (titanium nitride coated $\mathrm{CoCr}$ alloy dentures) revealed only three evident differences. The first difference was found in the acidophilic cell category in the $55-70 \%$ range which contained $16 \%$ of the CoCrTN group and none of the control group $\left(\mathrm{chi}_{\alpha}{ }_{\alpha}=\right.$ $=4.15966$ ). The second was in the category of all cells with nuclei where the 70-100\% range contained $16 \%$ of the patients from the CoCrTN group and none of the control group patients, and the third in the 4-8\% range of basophilic cells with nuclei, to which also $16 \%$ of the patients belonged but none of the control patients $\left(\mathrm{chi}^{2}{ }_{\alpha}=4.15966\right)$. In all three of these cell categories, there were no corresponding counterparts from the control group, and the results of the chi- -square test corresponded to situations with expected values of less than 5. In the ACRYL patient group (patients who used acrylic dentures), significant differences were noted in comparison with the control group in all the ranges of acidophilic cells: in the 0 $-55 \%$ range $\left(\mathrm{chi}_{\alpha}^{2}=5.57758\right)$, the 55-70\% range $\left(\mathrm{chi}^{2}{ }_{\alpha}=\right.$ $=7.93421)$ and in the $70-100 \%$ range $\left(\mathrm{chi}^{2}{ }_{\alpha}=\right.$ $=5.57758$ ). This corresponds to $33 \%$ of the patients from the ACRYL group in the first range (ten times more than the control group), $33 \%$ of the patients in the second range with no patients from the control group encountered in this range, and only $33 \%$ of the patients from the ACRYL group in the third range with $96 \%$ of the patients from the control group (three times fewer). In all, about $66 \%$ of the patients in the ACRYL group had significantly less acidophilic cells in smears (Figure 1B) than the control group (Figure 1A). There were no differences noted between the compared groups in the category of multi-staining cells. The following differences were observed compared to the control group: in the category of all cells with nuclei in the 70-100\% range $\left(\mathrm{chi}_{\alpha}^{2}=4.19549\right)$, in the category of multi-staining cells with nuclei in the $12-24 \%$ range $\left(\mathrm{chi}_{\alpha}^{2}=4.19549\right)$, and in the category of basophilic cells with nuclei in the 4-8\% range $\left(\mathrm{chi}^{2}{ }_{\alpha}=\right.$ $=4.19549)$. In the abovementioned categories, $16 \%$ of ACRYL group patients belonged to each of these ranges, while at the same time no patients from the control group exhibited these characteristics. In all of the three mentioned cases, the expected values were less than 5 .

There were no statistically significant differences found between the groups of $\mathrm{CoCr}$ and $\mathrm{CoCrTN}$ patients, and the CoCr group of patients and the ACRYL group in the analyzed cell categories and ranges. 
A comparison of the ACRYL and the CoCrTN groups revealed only one difference, in the category of all cells with nuclei in the $40-70 \%$ range $\left(\mathrm{chi}^{2}{ }_{\alpha}=\right.$ 4.22284) which corresponds to only $3 \%$ of the ACRYL group patients of in this range compared to $25 \%$ of the CoCrTN group patients.

A comparison of the keratinocyte foci amount between the control group and the study groups and between each of the study groups only revealed a significant difference between the control group and the CoCrTN group $\left(\mathrm{chi}^{2}{ }_{\alpha}=5.6667\right)$ where a lack of keratinocyte foci was rarer (only 50\%) in the patients with titanium nitride coated dentures than in the control group ( $81 \%$ of the subjects). The lack of granulocytes in the smears only exhibited statistical differences between the control and ACRYL groups compared to the CoCr group $\left(\mathrm{chi}_{\alpha}{ }_{\alpha}=5.6644\right.$ and $\mathrm{chi}_{\alpha}{ }_{\alpha}=4.84632$, respectively), because in the CoCr group granulocytes were not found in only $35 \%$ of the patients, whereas in the control group they were not found in $62 \%$ of the patients, and in the ACRYL group in $60 \%$ of the patients granulocytes were not present in the smears. Regarding the lack of erythrocytes in the smears, the only statistically significant difference was noted between the CoCr and CoCrTN groups $\left(\mathrm{chi}_{\alpha}^{2}=14.7246\right)$ because there were no patients using titanium nitride coated dentures in whose smears erythrocytes were observed, while these cells were not seen in only $84 \%$ of the $\mathrm{CoCr}$ group patients. No differences were found in the lack of bacterial cells in the smears among all of the investigated groups.

A comparison of these same groups, according to the number of numerous granulocytes in the smears, besides the classification based on groups, categories and populations of cells in the smear, revealed that granulocyte-free smears are most common in all of the study groups. This was the case in $88 \%$ of the control group $\left(\mathrm{chi}^{2}=11.6735\right)$, in $84 \%$ of the CoCr group $\left(\mathrm{chi}_{\alpha}{ }_{\alpha}=13.1625\right), 83 \%$ of the CoCrTN group $\left(\mathrm{chi}^{2}{ }_{\alpha}=\right.$ $=7.48052)$, and $96 \%$ of the ACRYL group $\left(\mathrm{chi}^{2}{ }_{\alpha}=\right.$ $=19.2892$ ).

An analysis of the frequency of different cells ranges in the different categories with the assumed criteria, i.e. that there is a large amount of granulocytes in the palatal epithelium smear, did not bring satisfactory results, because the number of patients in the different ranges was very small and the expected values in the chi-square table were less than 5 , which means that they did not meet the statistical credibility criteria of the test. For example, in the category of all acidophilic cells, no control group patients with a large number of granulocytes in the smear were found in either the $0-55 \%$ range or the $55-70 \%$ range, and all three of them made up the $100 \%$ of the $70-100 \%$ range. On the other hand, $95 \%$ ( 23 of the 24 patients in the group) of the patients with a small number, or complete lack of, granulocytes were found to be in this category. The result, that is the test statistic $\mathrm{chi}^{2}=$ $=4.29329$, describing the statistical difference in the frequency distribution of patients using titanium nitride coated $\mathrm{CoCr}$ alloy dentures exhibiting large numbers of granulocytes compared to their negligible number in the $0-55 \%$ range, is not credible, because it pertains to two out of 20 patients and one out of four patients.

\section{Discussion}

The palatal epithelium cytology results for the subjects in the control group are consistent with results reported by other authors [18]. Characteristics which can be reported as typical for the palatal epithelium smear include a high level of keratinization, which includes a high percentage of acidophilic cells, a low percentage of cells with nuclei and a small percentage of multi-staining and basophilic cells. The occurrence of granulocytes and erythrocytes in the patients was low (only $12 \%$ of the subjects), and bacterial cells were found only sporadically. This state is consistent with a full keratinization of the palatal epithelium and changes resulting from the individual oral hygiene of the patients, as well as all the positive and negative effects of individual eating habits, stimulants and other factors.

The results obtained for the experimental group (with acrylic dentures, $\mathrm{CoCr}$ alloy framework dentures and titanium nitride coated $\mathrm{CoCr}$ alloy framework dentures) differ significantly from the results obtained in the control group, although the increase in the amount of granulocytes, erythrocytes and bacteria was not significant (Table 1).

We can therefore assume, taking into account all considerations regarding the denture fabrication and condition, personal oral hygiene, temperature and type of diet, as well as tobacco and alcohol, that the changes described here are a result of the deleterious effect of the denture materials. Moreover, they show that every type of denture (acrylic, CoCr alloy framework and TiN-coated CoCr alloy framework) has an inhibitory effect on the keratinization of the palatal epithelium. Nevertheless, the changes in the degree of keratinization clearly differed depending on the type of material used for the denture fabrication. The results of the patients using acrylic dentures were the closest to the results of the control group (Table 1). The main cytological difference in this group was a decrease in the keratinization of the epithelium characterized by an increased number of patients with 
a lower percentage of acidophilic cells $(60 \%$ of the patients) and in only 16 of the patients by an increase in the number of all cells with nuclei including acidophilic, multi-staining and basophilic.

These results indicate that keratinization inhibition affects the majority of the subjects, but that the changes are profound and marked in only a small group. These results are consistent with those reported in other studies [18-20] where in epithelial smears confirmed by histopathological examinations, a decrease in the thickness of the layer of keratinized tissue was observed. In the case of acrylic dentures, the onset of keratinization inhibition begins relatively early after beginning to use the dentures (14 days), although the more pronounced keratinization changes (increase in the number of multi-staining cells) were connected to the surface roughness of the dentures [21]. The usage period of acrylic dentures in this study was significantly longer, and the increase in the amount of intermediate cells in $16 \%$ of the patients can be related to the probable increase in the surface roughness (a result of wear) of the acrylic dentures being used for a long period of time (around five years). On the other hand, changes suggesting allergic reaction to the components of the acrylic were not found in either the anamnesis, clinical or cytological examinations.

Palatal epithelium cytological changes in the groups of patients using $\mathrm{CoCr}$ alloy framework dentures and titanium nitride coated $\mathrm{CoCr}$ alloy framework dentures differed between each other and were markedly different from the changes noted in both the control group and (slightly less) in the acrylic denture group. The only differences found between the $\mathrm{CoCr}$ and the CoCrTN groups were in the lack of erythrocytes in the smears of the CoCrTN group and in the higher amount of granulocytes in the $\mathrm{CoCr}$ group smears. There were fewer acidophilic cells in the CoCr group compared to the control group, and in one third of the patients in this group nuclei-containing cells, of which some were acidophilic, made up more than $70 \%$ of all cells in the smear. Intermediate cells with nuclei were found in $60 \%$ of the patients in this group. This characteristic was found somewhat less frequently in the CoCrTN group, but there was no statistically significant difference.

Analysis of the results revealed at least three important phenomena. First, there are more cases in both the $\mathrm{CoCr}$ and the CoCrTN groups of inhibited epithelial keratinization than in the ACRYL group. Second, these changes are significantly more pronounced than in the ACRYL group, which is shown by "the shift" in the smears towards more intermediate nuclei-containing cells. Third, despite the lack of difference in age and a highly statistically significant difference in the usage period of the dentures, the changes are identical.

Although inhibition of keratinization is a common result of all prosthetic dentures which remain in contact with the palate, such pronounced and marked changes in keratinization may be related to the $\mathrm{CoCr}$ alloy properties, regardless of the presence/absence of a titanium nitride layer. This can be a result of the voltaic effect which produces a metal taste in the mouth [17]. CoCr alloy can be subject to corrosion as well as to a characteristic break-up into small particles (of the order of $0.2 \mu \mathrm{m}$ ), which demonstrate a toxic effect through the intracellular release of cobalt in large quantities [15]. Furthermore, as shown by experimental in vitro studies on cell cultures, these small particles may stimulate macrophage and fibroblast production of cytokines, consequently producing changes in bone resorption causing osteoclast generation.

It is difficult to say whether the observed pronounced changes in the degree of keratinization are only a result of corrosion and release of chromium or only of the cobalt release. Most probably, they are a result of the interaction of both factors (unless other, as yet unknown, factors play a role). The lack of a beneficial effect of the titanium nitride coating on the observed changes after a relatively short usage period of the dentures suggests that, in the case of $\mathrm{CoCr}$ alloy, the coating may not create a protective effect or may intensify the release of substances from the alloy. Previous corrosion studies [22] have demonstrated that TiN coating on CoCr alloy inhibits only the release of chromium ions, but increases the release of cobalt ions from the alloy. On the other hand, prostheses made from alloys rich in titanium, enjoy a documented, highly positive opinion in literature $[23,24]$ and the three-year survival rate of titanium crowns and bridges is $100 \%$ when there are no palatal cytological changes.

Metal alloys do not show a deleterious effect (even if they contain toxic elements) as long as they are resistant to corrosion. Passive surface layers have a decisive impact on the corrosion resistance of the commonest metals and alloys. A typical example of a nonnoble metal alloy compound is titanium which produces a passive titanium dioxide layer. This element exhibits a very high affinity for oxygen, and a new coating is immediately produced whenever the surface is damaged [25].

\section{Conclusions}

1. Every prosthetic restoration introduced into the oral cavity and remaining in direct contact with 
the palate exhibits a varied and harmful effect on the state of the palatal epithelium by disturbing its keratinization.

2. CoCr alloy dentures produce a significantly greater perturbation of keratinization compared to acrylic dentures.

3. There is no evidence to show that a titanium nitride coating of the $\mathrm{CoCr}$ alloy plays a protective role in the environment of the oral cavity.

\section{References}

1. Wataha JC. Principles of biocompatibility for dental practitioners. J Prosth Dent. 2001;86:203-209.

2. Trombetta D, Mondello MR, Cimino F, Cristani M, Pergolizzi S, Saija A. Toxic effect of nickel in an in vitro model of human oral epithelium. Toxicol Lett. 2005;159:219-225.

3. Gawkrodger D, Lewis F, Shah M. Contact sensitivity to nickel and other metals in jewelry reactors. J Am Acad Dermatol. 2000;43:31-36.

4. Kieć-Świerczyńska M. Przyczyny uczuleniowego, zawodowego zapalenia skóry rozpoznanego w Instytucie Medycyny Pracy w Łodzi w ostatnim pięcioleciu. Med Pr. 1993;44:539-544.

5. Messer RLW, Sanford B, Lucas LC. Effects of metallic ion toxicity on human gingival fibroblasts morphology. Biomaterials. 1999;20:1647-1657.

6. Messer RLW, Lucas LC. Evaluations of metabolic activities as biocompatibility tools: a study of individual ions' effects on fibroblasts. Dent Mater. 1999;15:1-6.

7. Messer RLW, Lucas LC. Cytotoxicity of nickel-chromium alloys: bulk alloys compared to multiple ion salt solutions. Dent Mater. 2000;16:207-212.

8. Hensten-Pettersen A, Jacobsen N. Perceived side effects of biomaterials in prosthetic dentistry. J Prosth Dent. 1991;65:138-144.

9. Stenman E, Bergman M. Hypersensitivity reactions to dental materials in a referred group in patients. Scand J Dent Res. 1989;97:76-83.

10. Spiechowicz E, Glanz P, Axell T, Chmielewski W. Oral exposure to a nickel-containing dental alloy of person with hypersensitive skin reaction to nickel. Contact Dermatitis. 1984;10:206-211.
11. Izdebska-Szymona K, Kopeć-Szlęzak J. Modulacja odpowiedzi odpornościowej przez metale ciężkie. Imm Pol. 1994;29:179-193.

12. Klotzer W. Biologische Aspekte der Korrosion. Dtsch Zahnärztl Z. 1985;40:1141-1145.

13. Spiechowicz E. Uczulenia na chrom i nikiel w protetyce stomatologicznej. Prot Stom. 1981;36:127-132.

14. Zaczkiewicz A, Czerwińska-Dihm I. Choroby zawodowe skóry w materiale Wojewódzkiego Ośrodka Medycyny Pracy w Bydgoszczy w latach 1979-1991. Med Pr. 1994;45:311-318.

15. Howie D, Rogers S, McGee M, Haynes D. Biologic effects of cobalt chrome in cell and animal models. Clin Orthop. 1996;329:217-232.

16. Weber H. Zum Korrosionsverhalten dentaler Legierungen. Dtsch Zahnarztl Z. 1985;4:254-260.

17. Weber H. In-vivo-Korrosionserscheinungen von gegossenen Restaurationen und deren Wechselwirkungen mit der Mundhohle. Dtsch Zahnarztl Z. 1988;43:343-348.

18. Harinasuta S, Howlett J. Keratinization of palatal mucosa beneath metal-based removable partial dentures. J Dent. 1992;20:152-155.

19. Akal U, Mocan A, Aydogan S, Oygur T, Bagci L, Comdeviren H. Keratinization of palatal mucosa beneath metal-based removable partial and acrylic-based complete dentures compared with normal palatal mucosa: a clinical cytological and histological study. J Marmara Univ Dent Fac. 1997;2:665-672.

20. Riber E, Kaber S. A 12-month study on changes in the barrier properties of denture-loaded palatal mucosa in immediate denture wearers. Scand J Dent Res. 1980;88:250-256.

21. Coca I, Kerschbaum T, Schwickerath H. Oberflachenneschaffenheit von Oberkiefer - Kunststoffbasisplatten auf die Schleimhaut. Dtsch Zahnarzt Z. 1975;30:139-147.

22. Łukomska-Szymańska M, Sokołowski J, Rylska D, Klimek L. Investigation of the corrosion resistance and the metal ion release from CoCr-based prosthetic dental alloy coated by TiN. Pol J Environ Stud. 2007;16:228-231.

23. Walter M, Boning K, Reppel P. Clinical performances of machined titanium restorations. J Dent. 1994;22:346-348.

24. Łukomska-Symańska M, Brzeziński PM, Zieliński A, Sokołowski. The connective tissue response to $\mathrm{Ti}, \mathrm{NiCr}$ and AgPd alloys. J Folia Histochem Cytobiol. 2010;48:339-345.

25. Klotzer W. Metalle und Legierungen - Korrosion, Toxikologie, sensibilisierende Wirkung (Teil I). ZWR. 1991;100:300-307.

Submitted: 1 January, 2011

Accepted after reviews: 14 November, 2011 